Article

\title{
Integration Journey: The Social Mobility Trajectory of Ethnic Minority Groups in Britain
}

\author{
Yaojun $\mathrm{Li}^{1,2}$ \\ ${ }^{1}$ Institute for Empirical Social Science Research, Xi'an Jiaotong University, Xi'an 710049, Shaanxi, China \\ 2 Department of Sociology and Cathie Marsh Institute for Social Research, University of Manchester, Manchester, \\ M13 9PL, UK; E-Mail: Yaojun.Li@manchester.ac.uk
}

Submitted: 8 March 2018 | Accepted:4 July 2018 | Published: 30 August 2018

\begin{abstract}
This article studies the processes of social mobility by the main ethno-generational groups in Britain. We compare the origin-education-destination (OED) links between the first- and second- generation ethnic minority groups with those of whites, with a particular focus on whether the second generation are getting closer to whites than do the first generation in the links, hence becoming increasingly integrated into the socio-economic lives of British society. Using data from the UK Household Longitudinal Study and adopting structural equation modelling (SEM) methods, we find strong evidence of first-generation setback, and some signs of second-generation catch-up. Indians and Chinese are making progress, but the two black groups and Pakistanis/Bangladeshis are lagging behind. The analysis shows persisting ethnic disadvantages in the labour market in spite of their high levels of educational achievement, and it also shows an emerging order of ethnic hierarchy, running from Indian, Chinese, black Caribbean, Pakistani/Bangladeshi to black African groups.
\end{abstract}

\section{Keywords}

ethnicity; generation; minorities; social mobility; UK

Issue

This article is part of the issue "Migration, Boundaries and Differentiated Citizenship", edited by Terry Wotherspoon (University of Saskatchewan, Canada).

(C) 2018 by the author; licensee Cogitatio (Lisbon, Portugal). This article is licensed under a Creative Commons Attribution 4.0 International License (CC BY).

\section{Introduction}

One of the most important features in contemporary British sociology is the ongoing debate on the patterns and trends of social mobility. Is mobility rising, declining or showing a trendless fluctuation? High levels of social mobility, in terms of both absolute and relative rates and in the downward as well as the upward directions, are usually taken as evidence of a vibrant and meritocratic society whilst low levels of mobility are emblematic of a rigid and exclusive society (Goldthorpe, 2013; Payne, 2017; Vandecasteele, 2016).

Social mobility research has consistently shown that there are marked class differences in educational attainment, occupational achievement and labour market earnings in British society. While there is little disagreement about this overall conclusion, there are different views about how social divisions are changing over time. In the numerous studies conducted over three decades, Goldthorpe and his colleagues (see, for example, Goldthorpe, Llewellyn, \& Payne, 1987; Goldthorpe \& Mills, 2008) hold that there is little change in mobility in British society, in terms of either absolute or relative rates. A somewhat more optimistic account is shown in findings by another group of researchers (Devine \& Li, 2013; Heath \& Payne, 2000; Lambert, Prandy, \& Bottero, 2007; Li \& Devine, 2011, 2014; Li \& Heath, 2016). While details differ, a common feature in these studies is the evidence they provide on signs of social progress, as exhibited by a small but significant rise in relative mobility rates. A third view is held by economists, arguing that social mobility is declining in Britain (Blanden, Goodman, Gregg, \& Machin, 2004).

While there are heated debates, a closer look would reveal greater commonality than difference. Among sociologists, the main issue is whether there are signs of 
weakening origin-destination associations. Goldthorpe's main argument is that mobility trends tend to show trendless fluctuations. But he and Mills also show rising relative mobility in the analysis of 'complete tables', namely, between male origins and conjugal households (Goldthorpe \& Mills, 2008, fig. 9). This kind of growing, although limited, openness is also found in Breen, Luijkx, Müller and Pollak's (2009) analysis of educational mobility and in Li and Heath's (2016) study of social mobility (Li \& Heath, 2016, fig. 3, panel a). Secondly, it is noted that the differences between sociologists and economists are more methodological than substantive in nature: the former use the occupation-based measure and the latter use the income/earnings-based measure in examining trends of intergenerational mobility. When the two measures are directly compared, the substantive findings are not much different (Erikson \& Goldthorpe, 2010). Furthermore, by using Mosteller's (1968) iterative adjustment method, Goldthorpe showed that 'analyses based on five-class mobility tables...capture a stronger intergenerational association than do quintile family income/earnings tables' (Goldthorpe, 2013, p. 439, emphasis in the original). Thus, in spite of the debates among exponents of the three theses, the overwhelming evidence points to the same basic conclusion, that is, while there are profound inequalities in British society, class mobility might be on the increase although directions of income mobility are less certain.

The possibility of a loosening social (class) structure calls for explanation. Goldthorpe and Mills (2008) attribute this to the rising participation rates of women in the labour market who compete with men for more advantaged positions. Breen et al. (2009) suggest that the welfare system adopted since the Second World War coupled with greater provision of educational opportunities may have reduced the class inequality in educational attainment in the developed countries although Sturgis and Buscha (2015) argue that the impact of educational expansion on social fluidity was both indirect and weak. $\mathrm{Li}$ and Heath (2016) suggest that the rising composition of ethnic minority members in the population may be an important contributing factor if the minorities do not follow the same pattern of social reproduction as do the majority group.

The addition of ethnicity as a separate dimension to mobility research poses a new challenge to the already complicated analysis but offers a new perspective. Do immigrants and their children in Britain have the same opportunities as do the majority group? Do they suffer greater downward mobility and experience a 'perverse openness' (Hout, 1984, p. 1393)? Earlier research tends to ignore the ethnic dimension due to insufficient ethnic minority samples in the datasets, such as the National Child Development Study (NCDS) of 1958 and the British Cohort Study (BCS) of 1970, the sources used by Blanden et al. (2004), and by Goldthorpe and his colleagues mentioned above. In recent years, more attention is being paid to ethnic social mobility. For in- stance, Platt (2005) examined the mobility profiles of children of black Caribbean and Indian heritages who were aged 8 to 15 in 1971 using the Longitudinal Study with linked records from the censuses of population in England and Wales from 1971 to 1991, and she found that black Caribbean and Indian families were less able than whites to transmit resources to their offspring. Heath and McMahon (2005) compared the mobility profiles of Irish, black Caribbeans, Indians and Pakistanis with white British using data from the General Household Survey (GHS) for the years 1985-1992. They found that 'class origins operated in much the same way among ethnic minorities as they did among British-born whites' (Heath \& McMahon, 2005, p. 411). More recently, Li and Heath (2016) used data from the GHS, the British Household Panel Survey (BHPS) and the UK Household Longitudinal Study (UKHLS) to look at the mobility trajectories of the main ethnic minority groups in Britain over four decades from the 1980s to the 2010s. They found that black Africans and Pakistanis/Bangladeshis faced even greater disadvantages than Platt (2005) found for black Caribbeans and Indians. These and other studies in this regard have provided significant insights to the origin-destination associations of the ethnic minorities in Britain. Yet they do not show how education mediates the origin-destination association, whether the role is similar for ethnic minorities as for whites, or whether the impact is stronger for the second than for the first generation. Given this, the present study seeks to make a contribution to scholarship in this regard by examining the ethno-generational differences in social mobility processes in contemporary UK society, namely, how the origin-destination association is mediated via education.

Addressing issues of ethnic mobility processes is arguably more difficult than that on the general population. Firstly, there is the distinction between migration and ethnicity to be made and, secondly, there is the multiplicity issue to consider as ethnic minority groups are frequently found to be more different from one another than they are as a whole from the white majority. Thus, addressing issues of ethnic integration requires investigation of how the 'fates' of different groupings change over time and/or across generations in terms of the interplay between family origin, educational attainment and labour-market (occupational) destination.

Figure 1 suggests a framework of analysis for ethnogenerational social mobility in terms of origin, education and destination (OED) relations. The solid thick line represents the majority group (white British in the present case), the thin line represents the first-generation, and the dashed line represents the second-generation, ethnic minority groups. In the origin-education $(\mathrm{OE})$ relations, the lines for the first- and the second- generation groups are set close to each other and to that of whites on the assumption that the educational attainment of the two generations and of whites would be similarly affected by family origins: parents tend to use whatever socio-economic resources at their command to 


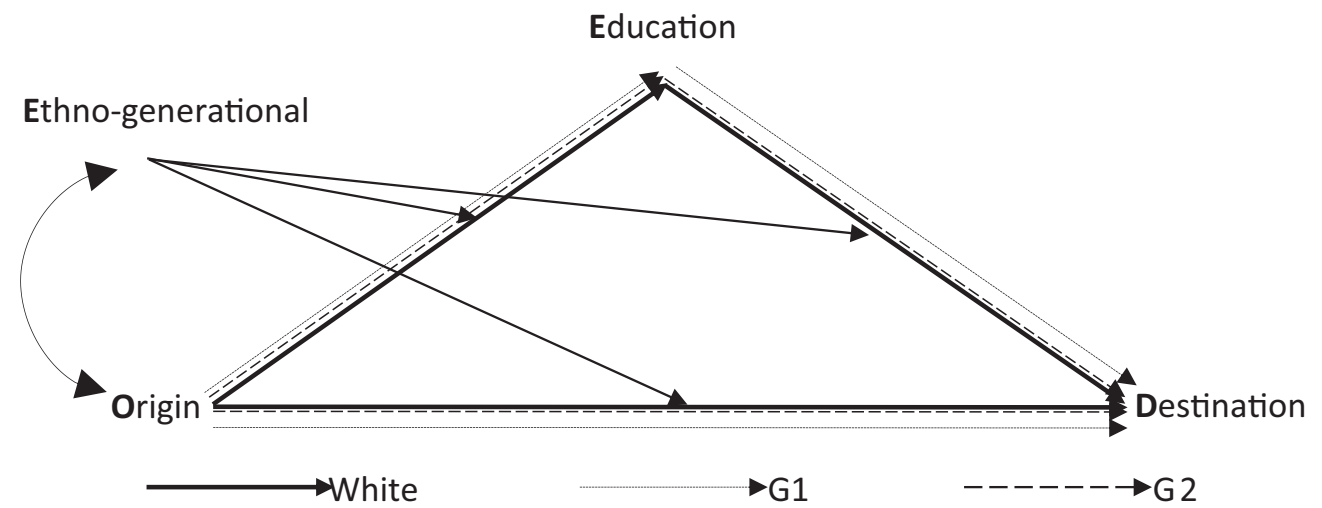

Figure 1. The OED moderated by ethno-generational status. Notes: First generation (G1) refers to ethnic minority respondents who were foreign born and who arrived in the UK at age 13 or older. Second generation (G2) refers to those who were UK born or who arrived in the UK by age 12. The lines for the first and the second generation ethnic minorities are placed outside of those for whites for convenience but the distances between the G1 and G2 lines with the white lines indicate the degree of integration.

help with their children's schooling and it is class, rather than ethnicity or nativity, that will play a predominant role in this regard. The extent to which this assumption will be borne out in reality is an empirical matter depending on the interplay between micro-level decisionmaking and macro-level economic conditions and employer preferences (for a discussion see Li, 2018). For the ED and OD relations, there is reason to believe that the two generations will have quite different trajectories, with the first generation to face more disadvantages in translating their educational qualifications into occupational achievement but the second to follow the majority group more closely. Immigrants tend to have overseas qualifications unrecognised by British employers, their parental resources are less functional in helping them obtain good jobs and, coming from developing countries, their parental resources are not expected to bear resemblance with those of whites. Overall, the immigrant generation are expected to have weaker associations in the ED and the OD relations than do the majority group, as is implied by the wider gaps between the first-generation and the white lines than between the second-generation and the white lines.

However, it can be expected that the first-generation setbacks will be largely avoided by the second generation who were born in the country or who arrived as children, and are thus raised and educated in the UK. Unlike their parental generation who might have a 'sojourner' orientation to their stay in Britain and may cherish the hope of returning to their country of origin, the second generation have a different orientation. For them, the UK is their country, English is their mother tongue, and British education is their passport to labour market achievement. Furthermore, unlike their parental generation whose migration process has disrupted their social networks with friendship ties left behind in the country of origin, the second generation will make friends with school mates, neighbours and others in the social circles just like their majority peers, with both bonding and bridging social capital to help them with their work and personal lives. In short, the human-social-economic capital of the second generation is expected to yield the essentially same returns to their occupational attainment as it does for whites. Even if there might be lingering disadvantages against the second generation, these can be expected to be negligible as compared with those faced by the first generation (Heath \& Li, 2008). Given these and other factors in favour of the second vis-à-vis the first generation, we may expect the second-generation to resemble whites in their educational and occupational attainment, or at least have ED and OD links much closer to whites' than to those of the first generation co-ethnics, as shown in the framework of Figure 1.

The distinction made in the foregoing discussion between the first and the second generation makes conceptual sense, but existing studies do not usually make such differentiations. On the whole, existing research suggests that ethnic minorities suffer marked disadvantages relative to whites, in terms of higher rates of unemployment, especially during recession years (also called 'hyper-cyclical unemployment' in the relevant literature), lower class positions and lower levels of earnings (Berthoud \& Blekesaune, 2006; Heath \& Li, 2008; Li, 2010, 2018; Li \& Heath, 2008, 2010, in press; NEP, 2007). Such studies also show considerable inter-ethnic differences, which exhibit themselves in a more salient manner than those that exist between ethnic minorities as a whole and whites. Some ethnic groups, such as those of black and Pakistani/Bangladeshi heritages, are usually found to face greater difficulties than do other groups. Given this, we need to differentiate both the main ethnic minority groups and the generational statuses.

As mobility research is primarily concerned with the strength of association between origins and destinations, an issue that is of central importance for analysing ethnic social mobility is whether ethnic minorities, the migrant generation in particular, have lower origin statuses than do the majority group in the destination country, 
white British in our case. As immigrants tend to come from poorer countries, we may expect them to have lower parental classes and lower educational qualifications than do whites. Existing research has, however, suggested that most immigrant groups in the UK were 'positively selected' not only as compared with their coethnics who have stayed in the origin countries but also with the mainstream population. This may sound surprising at first sight, but a moment's reflection would suggest this as an inevitable outcome of the raised thresholds of entry in the wave of the Race Relations Acts since the 1960s (Borjas, 1992; Feliciano \& Lanuza, 2017; Heath \& Brinbaum, 2014; Ichou, 2014; Li \& Heath, 2008). But the labour market setbacks they typically face would put them into lower class positions and poorer economic situations (Li, 2018), which would result in a lower starting point for the second generation. In such circumstances, the second generation may not follow white children in educational and occupational attainment. Empirical findings in this regard are inconclusive. Some studies have found the second generation faring better in education than do whites (Lessard-Phillips \& Li, 2017; Li, 2018), similarly well in occupational attainment (Cheung $\&$ Heath, 2007) but worse in avoidance of unemployment (Li \& Heath, 2008, 2016). An explanation for the secondgenerational educational success is provided in terms of 'reinvigorated aspiration' (Li, 2018), that is, parental depressed class would push them to redoubled efforts leading to higher levels of educational attainment as a preemptive strategy against the possible discrimination in the labour market. Overall, while there has been considerable research on separate OE, ED and OD links, no analysis is currently available that addresses the three links simultaneously for the ethno-generational groups in contemporary British society.

Summarising the discussion above, we wish to address the following questions in the present study:

- Do class origins exert the same influences on the educational and occupational attainment of the ethno-generational groups as for the white majority in Britain?

- Do the second generation experience greater similarity to whites than do the first generation in educational and occupational attainment? and

- Do men and women of ethnic minority backgrounds have similar experiences to their white peers in the OED trajectories?

\section{Data and Methods}

To address these questions, we use data from the first three waves of the UKHLS which has a large general population sample and an ethnic boost sample, enabling us to differentiate detailed ethno-generational groups, and which also contains rich information on parental socioeconomic position and respondents' own educational and occupational attainment. The data allow us to disaggregate the social mobility trajectories of different ethnogenerational and gender groups simultaneously, and to test whether processes of social reproduction operate for the majority and for different ethno-generational minority groups in a similar fashion. The survey started in 2009 and is the successor to the BHPS. From Wave 2 onwards, the BHPS respondents were 'rolled' into the UKLHS and their information is included in this analysis. ${ }^{1}$

For origin and destination, we adopt both class and status approaches. With regard to the former, we coded parental and respondent's class using the sevencategory National Statistics Socio-economic Classification (NS-SEC) schema: (1) higher salariat (higher-grade professionals and managers), (2) lower salariat (lowergrade professionals and managers), (3) intermediate (clerical and other routine non-manual workers of higher grades), (4) small employer and own account (excluding professionals), (5) lower supervisory and technical workers, (6) semi-routine, (7) routine workers. Including mother's class is important given recent research evidence (Beller, 2009; Li \& Devine, 2011). For parental class, we followed a variant of the dominance approach (Erikson, 1984) which takes the higher of father's or mother's class position if both parents' class information is available (which is usually father's position), or the nonmissing parent's class position if only one parent's occupational information is available. The class measure is used in addressing issues of class advancement or decline by the ethno-generational groups.

As for socio-economic status, we used information on both parents' and respondents' job titles and turned them into standard International Socio-Economic Index (ISEI) scores following the conversion programme designed by Ganzeboom, De Graaf and Treiman (1992). With regard to parental socio-economic status scores, we first coded father's and mother's ISEls and then used the Euclidian method ${ }^{2}$ to derive the family status, which can more accurately capture the advantages and disadvantages of different types of family, such as dual- over single- career families, in terms of the socio-economiccultural resources in their possession. For instance, the resources of one family where both parents were in senior (professional or managerial) salariat positions would be much greater than those of another family where one parent was in a senior salariat position but the other was a cleaner or shop assistant or non-employed, or where it was a single-parent family with, say, the mother working as a nurse. Using the dominance class approach would yield the same level of family class but with the Euclidian approach, the differences between them can be brought

\footnotetext{
${ }^{1}$ The response rates are high, at around $80 \%$ for the general population sample and $70 \%$ for the ethnic minority boost sample; see UK Data (n.d.).

2 Using the Euclidian method, the parental socio-economic status is defined as the square root of the sum of the squares on each parent's ISEIs when both parents' scores are available (sqrt of (father's ISEI^² + mother's ISEI^${ }^{\wedge}$ )) or the available score for one parent. As black Caribbean women are more likely to form single-parent households in Britain and as they are also frequently found to work as nurses in the NHS, using the dominance class approach would inflate the family resources they have relative to dual-career high-salariat families.
} 
into much sharper relief. The parental and respondent's status scores are used in assessing the OED relations via the structural equation modelling (SEM) method.

With regard to ethnicity, we follow the standard practice of ethnic studies in Britain and include white, black Caribbean, black African, Indian, Pakistani/Bangladeshi, Chinese, and 'Other'. As the main purpose in the article is to assess the ethnic integration, whites are used as the reference group for whom no generational divisions are further differentiated. Lessard-Phillips and Li (2017, p. 49) differentiated six generational groupings for white British and white Irish each, and five generational groupings for white Other, in their study of educational attainment; and Li and Heath (2008, 2010, 2018) also differentiated different white groupings (although not generational ones) in their study of long-term risks of unemployment, access to salariat positions and labour-market earnings, and found increasing convergence among the three groupings. Given this, whites in all generations are used as one broad group. The 'Other' group in our ethnicity variable is very diverse in composition, and we do not differentiate generations for them either. As for generational status, we define the first generation as those born outside the UK and arriving at age 13 or older, and the second generations as those born in the UK or arriving by age 12 on the grounds that, unlike the former, the latter would have received most (or all) of their education in Britain, and would acquire the same kind of human capital and have fluent English as whites. Higher generations are included in the second for each of the main ethnic minority groups (for detailed information on ethnic generations, see Lessard-Phillips \& Li, 2017). It is noted here that the first generation are not necessarily the parents of the second generation. Finally, in this regard, we need to bear in mind that while some ethnic groups tend to have stronger community ties which may foster higher levels of 'ethnic capital' conducive to children's educational attainment (Modood, 2004), the bonding ties may also place a particular emphasis on tradition and culture leaving a negative impact on female participation in the labour market (Portes, 1998). Given the complex interplay between ethno-generational and gender divisions, we conduct the analyses for men and women separately. We confine our study to respondents aged 16 to 65 for men and 16 to 63 for women. The sample sizes for the seven ethnic groups are 36,503, 891, 1,140, 1,722, 1,895, 268 and 1,913 respectively.

Our main concern with the ethno-generational social mobility in Britain includes two sub-themes: net social mobility between parents' and respondents' class positions, and origin-destination associations as mediated by education. To address the first issue, we use the net dissimilarity index (NDI) designed by Lieberson (1975; for application in mobility research see also Li \& Heath, 2016):

The NDI is defined as NDxy $=\operatorname{pr}(X>Y)-\operatorname{pr}(Y>X)$ and further defined as

$$
\sum_{i=2}^{n} x_{i}\left(\sum_{j=1}^{n=i-1} y_{j}\right)-\sum_{i=2}^{n} y_{i}\left(\sum_{j=1}^{n=i-1} x_{j}\right)
$$

where, in our case, $X$ indicates the parental class position and $Y$ that of the respondent. It is noted here that we reversed the class order in calculating the NDI with 1 referring to the routine manual and 7 to the higher salariat.

Mobility researchers tend to use the dissimilarity index (DI) which shows the percentage of cases that would have to be reallocated to make the two distributions identical as a measure of the overall difference between two distributions. Yet the $\mathrm{DI}$ is insensitive to ordering and does not provide any directional statement about the differences between father's and respondent's classes. The NDI, however, does provide a directional statement about class decline or advancement, with a positive value indicating net upward, and a negative value indicating net downward, mobility. The range of the NDI is from -1 to 1 in Lieberson's original article but is here rescaled to range from -100 to 100 so that the scales could be understood akin to percentage-point differences. To address the second issue we use SEM with parental and respondent's ISEI scores to represent origin and destination status positions. For education, we follow Duncan (1968, p. 92) in using levels rather than years of education and we code an eight-way variable: (1) no formal education, (2) primary, (3) GCSE (O-Level) or equivalent, (4) incomplete A-Level, (5) A-Level or equivalent, (6) subdegree, (7) first degree and (8) higher degree (masters or PhDs).

\section{Results}

We begin by looking at class and educational distributions by ethnic groups and by gender. For class, we also look at advancement or decline as shown in the NDI in Table 1 based on parents' and respondents' seven-class distributions. As the presentation of all these distributions would take too much space, we only show the proportions of parents and respondents in salariat positions. Again, for brevity, we only show the proportions with (first or higher) degree qualifications by respondents. The data on degree-level education are presented here to give an indication of possible mechanism of class decline or advancement. The majority group (white) are used as the notional reference group in this table even though only univariate rather than multivariate analysis is conducted.

The data in Table 1 show two main features: firstgeneration class decline, and second-generation catchup. Both features are displayed within the overall structure of class rigidity and ethnic disadvantage of British society. The features can be better grasped by looking at the figures for whites for whom $34 \%$ of the parents, $39 \%$ of male and $36 \%$ of female respondents are in salariat positions, and $23 \%$ have degree levels of education. With these as benchmark figures, we find a salient 
Table 1. Parental and respondents' salariat positions (\%), net difference index (NDI) for intergenerational class advancement, and respondents' degree-level education (\%) by ethnicity, generation and gender $(\mathrm{N}=44,332)$. Source: The UKHLS waves 1-3.

\begin{tabular}{|c|c|c|c|c|c|c|c|c|}
\hline & \multicolumn{4}{|c|}{ (\%) salariat } & & & & \\
\hline & \multicolumn{2}{|c|}{ Parents } & \multicolumn{2}{|c|}{ Respondents } & \multicolumn{2}{|c|}{$\mathrm{NDI}$ on class advancement } & \multicolumn{2}{|c|}{ (\%) degree ${ }^{+}$} \\
\hline & 1st gen & 2nd gen & 1st gen & 2nd gen & 1st gen & 2nd gen & 1st gen & 2nd gen \\
\hline \multicolumn{9}{|l|}{ Men } \\
\hline White & - & 34 & - & 39 & - & 1.0 & - & 23 \\
\hline B Caribbean & 23 & 34 & 27 & 35 & -15.1 & -7.8 & 21 & 18 \\
\hline B African & 47 & 57 & 35 & 38 & -27.7 & -22.5 & 43 & 31 \\
\hline Indian & 40 & 30 & 43 & 53 & -10.1 & 30.1 & 53 & 39 \\
\hline Pak/Ban & 34 & 14 & 24 & 31 & -24.5 & 19.8 & 37 & 26 \\
\hline Chinese & 55 & 24 & 51 & 45 & -11.7 & 3.7 & 65 & 47 \\
\hline Other & 39 & 46 & 34 & 42 & -20.3 & -11.8 & 43 & 28 \\
\hline \multicolumn{9}{|l|}{ Women } \\
\hline White & - & 34 & - & 36 & - & -0.3 & - & 23 \\
\hline B Caribbean & 21 & 30 & 30 & 39 & 1.8 & 16.7 & 20 & 27 \\
\hline B African & 46 & 51 & 29 & 31 & -33.9 & -22.5 & 31 & 34 \\
\hline Indian & 41 & 26 & 33 & 39 & -18.1 & 22.5 & 41 & 32 \\
\hline Pak/Ban & 29 & 15 & 28 & 26 & -14.2 & 25.7 & 19 & 22 \\
\hline Chinese & 58 & 22 & 51 & 42 & -21.6 & 8.5 & 56 & 38 \\
\hline Other & 40 & 41 & 38 & 37 & -14.7 & -4.4 & 38 & 25 \\
\hline
\end{tabular}

Notes: 1st and 2nd gen refer to first and second generations. For analysis of the NDI, the seven-class schema for parents and respondents is used for each of the ethnic minority groups by generation and by gender. Weighted analysis for this and all other analyses in this study.

feature of first-generation 'positive selection' followed by subsequent class decline, and second-generation educational achievement. The term 'positive selection' is usually used to refer to the socio-economic resources of movers relative to stayers in the origin country, not to the majority group in the destination countries. Most immigrants to the UK come from developing countries and one might expect them to have poor family class and low education. Yet, the data on proportions of parental salariat and own degree-level education of our firstgeneration respondents suggest that they are not only highly positively selected relative to their compatriots who stayed in the origin countries but also compare well with the majority group in the UK. We do not, of course, have direct evidence on parental and own resources for stayers in all the source countries from which our firstgeneration respondents come, but we do have evidence on China which renders strong support to the intuitive thinking. ${ }^{3}$ Most ethno-generational groupings are, with the exceptions of black Caribbean men and women and Pakistani/Bangladeshi women, as likely as or more likely than whites to have salariat parents and degree-level education. $65 \%$ of Chinese and $53 \%$ of Indian men in the first generation have degree-level education, over twice as high as for white men (23\%). The parental class advantage of first-generation men is also clear, especially by
Chinese and black African men, at $55 \%$ and $47 \%$ respectively, as against $34 \%$ for white men. This gives substantial evidence on the immigrant positive selection in the UK as compared not only with their fellow-countrymen who have stayed in the origin country but also with the white British. One might, of course, argue that immigrants' parental salariat position and their own degreelevel education do not carry the same returns to labour market positions in Britain as do those for whites. This may be true to some extent. For instance, a farmer in India may not have as much land as his counterpart in Britain. But if we take a relative position, in terms of the proportion of compatriots who do not have similar levels of resources, then it makes sense to say that immigrants tend to have better economic resources and human capital than do their compatriots who have stayed in the home country and it is this 'superior' position before, coupled with class decline after, immigration which may well serve as a source of reinvigorated aspiration to their offspring (Li, 2018).

When we compare the first- and the second- generation's parental class positions, we find clear evidence of immigrant class decline. As our second generation are those born in the UK or arriving by age 12 , their parents' class position is indexed by the jobs they were doing in the UK labour market, hence measured in a

\footnotetext{
${ }^{3}$ For men aged $25-69$ in China, only $11 \%$ of the parents and $14 \%$ of the respondents were in salariat positions (Li, Zhang, \& Kong, 2015, p. 25). The Chinese immigrant men's class positions were therefore not only much higher than those of their fellow countrymen in China but also higher than those of the white British.
} 
way comparable to that of white parents. As compared with whites, we find that all second-generation groups' parental class is lower than that of whites with the exception of black Africans. The immigrant class decline can also be seen from comparing the first- and the second- generation's own class positions. Although both generations have much higher levels of education than do whites (except for black Caribbean men and Pakistani/Bangladeshi women), their proportions in salariat positions are generally lower than for whites (except for Chinese and Indians).

The interplay between parental and respondents' class positions may present itself as class decline or advancement, as is captured by the NDI under the middle columns of Table 1 . Here we see clear evidence of first-generation class decline and some evidence of second-generation advancement. With the sole exception of black Caribbean women, all first-generation men and women in all ethnic minority groups suffered class setbacks: in other words, they worked in jobs at a lower level than that of their parents. Amongst the second generation, Indian, Pakistani/Bangladeshi men and women, and black African women were finding themselves in higher occupational levels than their parents. Most of these features apply to ethnic minority groups of both sexes to a fairly similar extent although women tend to have lower class positions and educational qualifications than do their male counterparts.

The analysis above gives fairly clear evidence of positive-selection and class setback by the migrant- (and some advancement for the second-) generation. Yet the analysis is at a descriptive level. Moving from this, we now turn to a more formal test, to see how family origin affects the respondent's education which in turn affects their class destination using the SEM method.

In the SEM framework for OED analysis, the effects of OE, ED and OD links are simultaneously assessed. The coefficient for the OD link is called 'direct' effect, the multiplication of the OE and the ED coefficients is called 'indirect' effect, and the sum of the direct and the indirect effects is called 'total' effect. The five effects for the ethnogenerational groups by sex are summarised in Table 2, all measured as standardised coefficients. By comparing the coefficients of the ethno-generational groupings with those of whites, we can see whether the strength of association is significantly different, hence whether a particular group is successfully integrated into British society in the domains under consideration. Similarly, by comparing the changes between the first and the second generations, we can gain insights into whether a particular group is making significant progress over generations. ${ }^{4}$ Our main interest here is to see whether the second generation is much closer than the first generation to whites in each of the links. As ethnic minorities tend to be younger than whites, we have included age as a covariate in all models. Younger cohorts may, for instance, have benefited from the expansion of higher education and of salariat class in British society than older ones. ${ }^{5}$

The data in Table 2 show some important features. First, when all factors in the models are taken into account, the effects of education on destination (ED) are much more salient than the effects of origin on destination (OD). With the sole exception of second-generation Chinese women, the coefficients on the ED link are highly significant for all ethno-generational groupings. But we need to remind ourselves that origin effects are mediated via education and that, in addition to separate ED effects, there are still sizeable direct and indirect effects. Thus, the origin effects manifest themselves in a powerful, albeit not always direct, manner since the mediating effects are mostly stronger than the direct effects. Second, with the sole exception of first-generation black Caribbean men who have been found to have the lowest education in Table 1 and who here show a significantly stronger ED association than for white men, there are no significant differences in the ED link between the ethnogenerational groupings and their white peers. This, however, does not mean the education has the same returns for minorities as for the majority group. As shown in the emboldened figures, there are significantly weaker indirect and total effects for the second-generational men and women than for whites, which may explain why the second-generation members are so much better qualified but have worse labour market outcomes as frequently observed in research. And third, looking at the generational changes as indicated by italicised figures on the second generation, we find that second-generation black Caribbean men have significantly weaker indirect and total effects than their first-generation counterparts, as do Indian men's OE and Indian women's indirect links. The mechanisms in these cases may be different. As for black Caribbean men, it may be the 'downward spiral' to the white working class norms and aspirations as discussed in Li and Heath (2008) which may explain their greater integration. For Indians, the first-generation class decline and second-generation success may better explain their intergenerational advancement and the loosening links over the generation.

The findings on a greater distance between the second than between the first generation ethnic minority groups and whites in the mobility pathways run counter to the expectations as specified in Figure 1 and also seem counter-intuitive. For decades, ethnic studies scholars have been predicting over time and intergenerational progress in assimilation (Alba, 2005; Gordon, 1964; Li, 2010; Park \& Burgess, 1921/1969). So, how do we make sense of the findings? Firstly, we need to think how the weaker strength of association comes about. If one group cannot pass the resources to their offspring as effectively as another, this would weaken the strength of origin-destination associations. Duncan (1968), for instance, shows that black people in the US were poor

\footnotetext{
${ }^{4}$ Significance tests in both regards are conducted via the procedure of 'nonlinear combination of estimators' (nlcom in Stata) within the SEM structure. ${ }^{5}$ I wish to thank an anonymous reviewer and the Academic Editor for this insightful point.
} 
Table 2. Standardised coefficients for the OED by ethno-generational groups and sex. Source: The UKHLS waves 1-3.

\begin{tabular}{|c|c|c|c|c|c|}
\hline & $\mathrm{OE}$ & ED & OD & Indirect & Total \\
\hline \multicolumn{6}{|l|}{ Men } \\
\hline White & $.316 * * *$ & $.456 * * *$ & $.087^{* * *}$ & $.157^{* * *}$ & $.239 * * *$ \\
\hline G1: Black Caribbean & $.411 * * *$ & $.732 * * *$ & .013 & $.339 * *$ & $.316^{*}$ \\
\hline G1: Black African & $.246 * * *$ & $.424 * * *$ & .050 & $.107^{* * *}$ & $.158^{*}$ \\
\hline G1: Indian & $.248 * * *$ & $.442 * * *$ & $.097 *$ & $.126 * * *$ & $.206 * * *$ \\
\hline G1: Pakistani/Bangladeshi & $.285^{* * *}$ & $.428 * * *$ & .001 & $.120 * * *$ & $.125^{*}$ \\
\hline G1: Chinese & $.259 *$ & $.312^{* *}$ & .091 & .069 & .179 \\
\hline G2: Black Caribbean & $.195^{*}$ & $.317^{* * *}$ & -.063 & .062 & -.008 \\
\hline G2: Black African & .198 & $.558 * * *$ & -.068 & .111 & .025 \\
\hline G2: Indian & .075 & $.508 * * *$ & .109 & .044 & $.184^{* *}$ \\
\hline G2: Pakistani/Bangladeshi & .127 & $.480 * * *$ & -.020 & .066 & .043 \\
\hline G2: Chinese & .142 & $.650 * * *$ & .127 & .097 & .215 \\
\hline Other & $.235 * * *$ & $.433^{* * *}$ & .074 & $.109 * * *$ & $-.086 * * *$ \\
\hline \multicolumn{6}{|l|}{ Women } \\
\hline White & $.356 * * *$ & $.465 * * *$ & $.066 * * *$ & $.165^{* * *}$ & $.231^{* * *}$ \\
\hline G1: Black Caribbean & $.357 * * *$ & $.487^{* * *}$ & -.002 & $.174 *$ & .172 \\
\hline G1: Black African & $.274 * * *$ & $.424 * * *$ & $.141^{*}$ & $.116^{* * *}$ & $.257^{* * *}$ \\
\hline G1: Indian & $.348 * * *$ & $.548 * * *$ & .053 & $.191 * * *$ & $.244^{* * *}$ \\
\hline G1: Pakistani/Bangladeshi & $.326 * * *$ & $.392 * * *$ & .201 & $.128 * * *$ & $.329 * * *$ \\
\hline G1: Chinese & $.298 * *$ & $.381 * * *$ & .166 & $.114^{*}$ & $.279 *$ \\
\hline G2: Black Caribbean & .096 & $.451 * * *$ & -.058 & .043 & -.014 \\
\hline G2: Black African & .219 & $.364 * * *$ & .101 & .080 & .181 \\
\hline G2: Indian & $.237 * * *$ & $.370 * * *$ & .041 & $.088 * * *$ & .129 \\
\hline G2: Pakistani/Bangladeshi & $.214^{* *}$ & $.416 * * *$ & .024 & $.089 * *$ & .113 \\
\hline G2: Chinese & .229 & .085 & .406 & .019 & .426 \\
\hline Other & $.247 * * *$ & $.447^{* * *}$ & $.120 * * *$ & $.111 * * *$ & $.231 * * *$ \\
\hline
\end{tabular}

Notes: ${ }^{*} \mathrm{p}<.05,{ }^{* *} \mathrm{p}<.01,{ }^{* * *} \mathrm{p}<.001$. Significant differences between the ethno-generational groupings and whites (at the 0.05 level or above) are shown in bold, and significant differences between the first and the second generations of a particular group are shown in italics and placed on the coefficients for the second generation.

not because they were born into poverty but because they were born black. In this case, advantaged class origins had less importance for the mobility chances of blacks than for whites, exhibiting a greater fluidity or a 'perverse openness'. Essentially what Duncan is arguing about here is that whilst most blacks in the US were in very low positions, some would achieve occupational success; but even for these lucky ones holding professional-managerial positions, their children may still face higher risks of downward mobility than for their white peers. Secondly, we need to think about not only parental position but that of the respondents as well. We have noted above that most immigrants suffered class decline and that the second-generation's education was on the whole higher and their class position lower than those of whites. Thus, relative to the first generation, the second-generation's much lower starting-point and still lower end-point would also imply a weaker origindestination association.

Finally, we show, in Figure 2, a summary picture of the ethnic integration trajectory over generations in Britain. The data chart the changing fortunes of the first and the second generations starting from parental class to own education and destination (OED) where we also include avoidance of unemployment (D1 in the figure) as part of the labour market position. Unemployment is an important area of ethnic disadvantage, but it is hard to integrate this into the SEM framework methodologically. However, we can obtain the net effects using logit model. The data are shown for men and women separately.

Figure 2 clearly shows that the ethnic minority groups suffer in the British labour market. Even though their family position is generally high, and their own education is well above that of whites, they encounter much higher risks of unemployment and enjoy much lower access to advantaged (salariat) positions. For instance, Chinese men's degree-level education is 34 percentagepoints higher than that of white men but their salariat occupancy is 7 points lower, net of all confounding factors which have been controlled for in the models, with a differential of 41 points. The corresponding figures are 36, 31, 29 and 7 points for Indian, Pakistani/Bangladeshi, black African and black Caribbean men. The first-generation's class position (D2) would generally serve as parental class situation for the second generation, which is much lower than that of whites. Yet, even though they start from such disadvantaged positions, the second generation, with the sole exception 


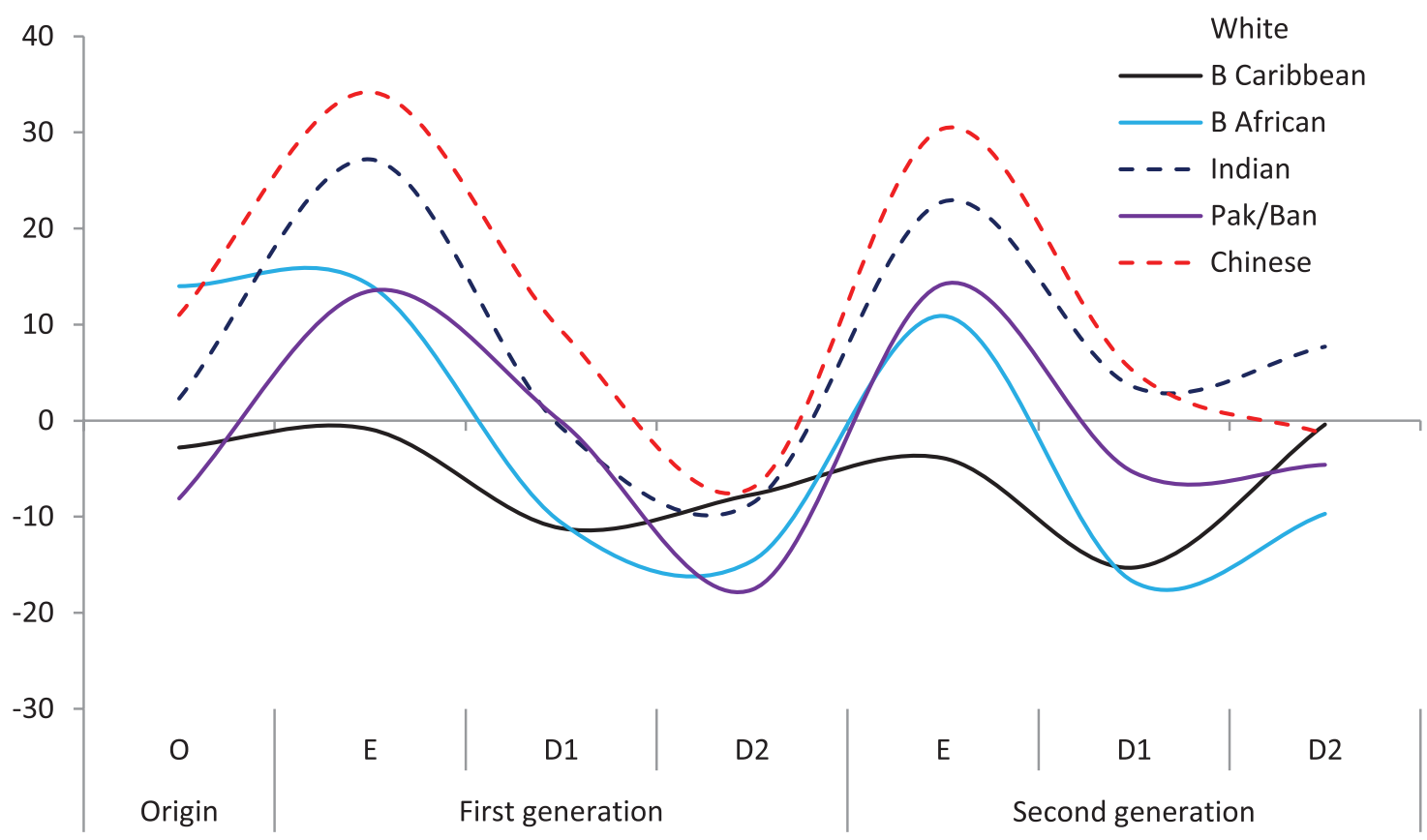

(1) Men.

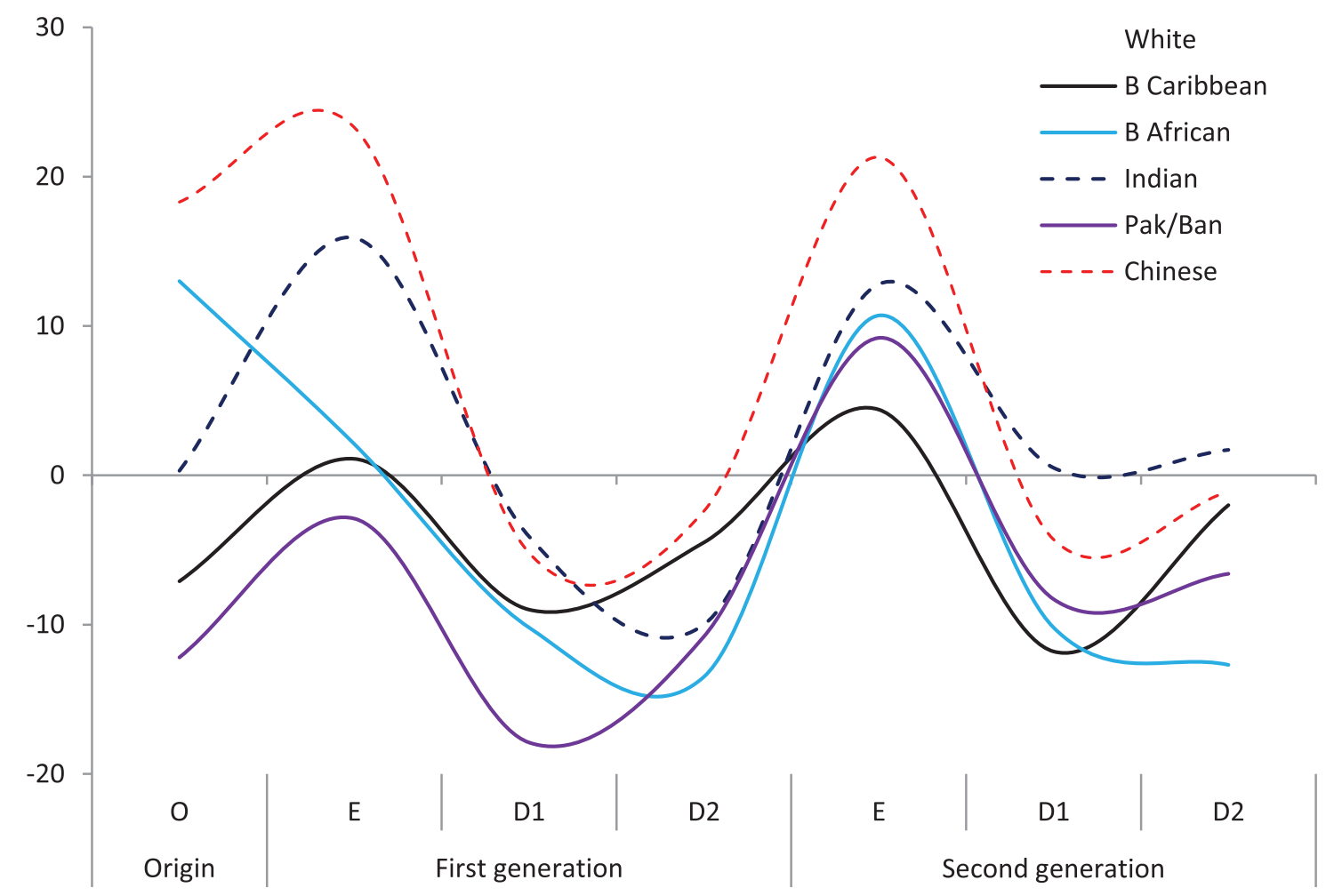

(2) Women.

Figure 2. Integration trajectories of ethno-generational groups by sex. Notes: Whites' values are set at 0 and those of ethnogenerational groupings are expressed as net differences from whites, in terms of percentage points. O: parental salariat positions; E: respondent's degree-level education; D1: respondent's avoidance of unemployment; D2: respondent's access to salariat. Parental class, age, age squared and ethno-generational status are included in estimating degree-level education, and education is further included in modelling unemployment and access to salariat. All data points except $O$ are average marginal effects (AME) from the relevant models. 
of black Caribbean men, still manage to acquire much higher education than white men, only to face higher unemployment rates and lower chances of career progression in their own labour market position. The same situation is found for women albeit to a smaller extent.

\section{Discussion and Conclusion}

This study analysed the processes of social mobility by ethnic minority groups over generations in contemporary Britain. We used the OED framework for assessing whether the ethnic minority groups in their first and second (or higher) generations experienced similar processes of social mobility with increasing social integration. Drawing data from the UKHLS and adopting the SEM procedure, we paid particular attention to whether the second-generation ethnic minority groups would approximate whites in the processes of social mobility. The first generation is expected to experience setback due to language barriers, overseas qualifications, lack of knowledge of local labour market, and overt or covert forms of racial discrimination but the second generation is expected to experience no such social exclusion.

Whilst our analysis does show serious setbacks by the first generation, the second generation's OE/OD links and indirect and total effects are rather weak, suggesting significantly greater fluidity than in the white pattern, forming an apparent paradox unpredicted from the classical theories. Yet, closer reflection suggests that the patterns that manifest themselves are well-grounded. As compared with whites, ethnic minority families may be better able to foster upward mobility just as they are less able to prevent downward mobility. In other words, ethnic minority children from lower family positions would be more instilled to perform well in education than white children from similar origin classes, just as those from higher family positions would be more likely to experience downward mobility due to inadequate or less effective bridging social capital possessed by their parents. Our analysis does show that in spite of their humble family origins, the second generation outperform their white peers in education but their excellences in human capital do not bring them equal returns to labour market positions. With so much higher educational credentials, they are still behind whites in avoidance of unemployment and in salariat occupancy. Further analysis reveals that, even among those with degree levels of education, they are significantly behind whites $(69 \%$ and $76 \%$ for second-generation and white men respectively in salariat occupancy). ${ }^{6}$

Overall, our analysis, which we believe is the first systematic attempt at exploring the OED relations for ethnogenerational and gender groups using the most authoritative data sources in the UK, shows that members of ethnic minority backgrounds have taken a long and bumpy journey in Britain. There is clear evidence of persisting ethnic inequality over generations. There are also signs of a growing ethnic polarisation, as shown by the class declines experienced by both generations of black Africans. Prime Minister May (2017) said that the continued disadvantages by ethnic minorities in Britain must be 'explained or changed'. Our evidence shows such persisting ethnic disadvantages, hence the serious needs for overcoming issues of social exclusion. This is a challenge for the government, employers and wider society alike.

\section{Acknowledgements}

I wish to thank Professor Anthony Heath at Nuffield College, Oxford University, attendants at the Runnymede Conference on Race and Class held at LSE, May 2015, attendants at the Social Mobility and Labour Market Symposiums, April 2018, at Cathie Marsh Institute for Social Research, Manchester University, the five anonymous reviewers and the academic editor of this issue for their insightful comments and suggestions on the earlier versions of the article. I am grateful to the UK's Economic and Social Research Council (ESRC) and Engineering and Physical Sciences Research Council (EPSRC) for funding the projects for this research: Socio-Economic Position of the Minority Ethnic Groups in Britain (RES163-25-0003, as PI), Social Mobility and Social Capital in China and Britain (ES/I035168/1, as PI), Understanding the Dynamics of Ethnic Identity and Inequality in the UK (ES/J020036/1, as Co-PI), and The Social Complexity of Immigration and Diversity, (EP/H02171X/1, as Co-PI). And I also wish to thank the Institute for Empirical Social Science Research (IESSR), Xi'an Jiaotong University, China, for providing facilities for conducting part of the analysis reported in the article during my stay there as a visiting professor. I am alone responsible for the errors in the article.

\section{Conflict of Interests}

The author declares no conflict of interests.

\section{References}

Alba, R. (2005). Bright vs. blurred boundaries: Secondgeneration assimilation and exclusion in France, Germany and the United States. Ethnic and Racial Studies, 28(1), 20-49.

Beller, E. (2009). Bringing intergenerational social mobility research into the twenty-first century: Why mothers matter. American Sociological Review, 74(4), 507-528.

Berthoud, R., \& Blekesaune, M. (2006). Persistent employment disadvantage, 1974 to 2003 (Working Paper of Institute for Social and Economic Research 2006-09). Colchester: University of Essex.

Blanden, J., Goodman, A., Gregg, P., \& Machin, S. (2004).

\footnotetext{
${ }^{6}$ Our data do not show whether the qualifications were obtained from Oxbridge or other Russell Group universities. This is a task for future analysis when appropriate data become available.
} 
Changes in intergenerational income mobility in Britain. In M. Corak (Ed.), Generational income mobility in North America and Europe (pp. 122-146). Cambridge: Cambridge University Press.

Borjas, G. (1992). Ethnic capital and intergenerational mobility. Quarterly Journal of Economics, 107(1), 123-150.

Breen, R., Luijkx, R., Müller, W., \& Pollak, R. (2009). Nonpersistent inequality in educational attainment: Evidence from eight European countries. American Journal of Sociology, 114(5), 1475-1521.

Cheung, S., \& Heath, A. (2007). Nice work if you can get it: Ethnic penalties in Great Britain. In A. Heath \& S. Cheung (Eds.), Unequal chances: Ethnic minorities in Western labour markets (pp. 505-548). Oxford: Oxford University Press.

Devine, F., \& Li, Y. (2013). The changing relationship between origins, education and destinations in the 1990s and 2000s. British Journal of Sociology of Education, 34(5/6), 766-791.

Duncan, O. D. (1968). Inheritance of poverty or inheritance of race? In D. Moynihan (Ed.), On understanding poverty (pp. 85-110). New York, NY: Basic Books.

Erikson, R. (1984). Social class of men, women and families. Sociology, 18(4), 500-514.

Erikson, R., \& Goldthorpe, J. H. (2010). Has social mobility in Britain decreased? Reconciling divergent findings on income and class mobility. British Journal of Sociology, 61(2), 211-230.

Feliciano, C., \& Lanuza, Y. (2017). An immigrant paradox? Contextual attainment and intergenerational educational mobility. American Sociological Review, 82(1), 211-241.

Ganzeboom, H. B. G., De Graaf, P., \& Treiman, D. (1992). A standard international socio-economic index of occupational status. Social Science Research, 21(1), 1-56.

Goldthorpe, J. H., Llewellyn, C., \& Payne, C. (1987). Social mobility and class structure in modern Britain. Oxford: Clarendon Press.

Goldthorpe, J. H. (2013). Understanding-and misunderstanding-social mobility in Britain: The entry of the economists, the confusion of politicians and the limits of educational policy. Journal of Social Policy, 42(3), 431-450.

Goldthorpe, J. H., \& Mills, C. (2008). Trends in intergenerational class mobility in modern Britain: Evidence from national surveys. National Institute Economic Review, 205(1), 83-100.

Gordon, M. (1964). Assimilation in American life: The role of race, religion and national origins. New York, NY: Oxford University Press.

Heath, A., \& Brinbaum, Y. (Eds.). (2014). Unequal attainments: Ethnic educational inequalities in ten Western countries (Proceedings of the British Academy 196). Oxford: Oxford University Press.

Heath, A., \& Li, Y. (2008). Period, life-cycle and generational effects on ethnic minority success in the labour market. Kölner Zeitschrift für Soziologie und Sozialpsychologie, 48(October), 277-306.

Heath, A. F., \& McMahon, D. (2005). Social mobility of ethnic minorities. In G. Loury, T. Modood, \& S. Teles (Eds.), Ethnicity, social mobility and public policy: Comparing the US and UK (pp. 393-413). Cambridge: Cambridge University Press.

Heath, A., \& Payne, C. (2000). Social mobility. In A. H. Halsey \& J. Webb (Eds.), Twentieth-century British social trends (254-278). Basingstoke: MacMillan.

Hout, M. (1984). Status, autonomy, and training in occupational mobility. American Journal of Sociology, 89(6), 1379-1409.

Ichou, M. (2014). Who they were there: Immigrants' educational selectivity and their children's educational attainment. European Sociological Review, 30(6), 750-765.

Lambert, P., Prandy, K., \& Bottero, W. (2007). By slow degrees: Two centuries of social reproduction and mobility in Britain. Sociological Research Online, 12(1). Retrieved from www.socresonline.org.uk/ 12/1/prandy.html

Lessard-Phillips, L., \& Li, Y. (2017). Social stratification of education by ethnic minority groups over generations in the UK. Social Inclusion, 5(1), 45-54.

Li, Y. (2010). The labour market situation of minority ethnic groups in Britain and the USA. EurAmerica: A Journal of European and American Studies, 40(2), 259-309.

Li, Y. (2018). Against the odds? Educational attainment and labour market position of the second generation minority ethnic members in the UK. Ethnicities. http://dx.doi.org/10.1177/1468796818777546

Li, Y., \& Devine, F. (2011). Is social mobility really declining? Intergenerational class mobility in Britain in the 1990 s and the 2000s. Sociological Research Online, 16(3), 1-15. Retrieved from www.socresonline.org. uk/16/3/4.html

Li, Y., \& Devine, F. (2014). Social mobility in Britain, 19912011. In L. Archer, A. Mann, \& J. Stanley (Eds.), Understanding employer engagement in education: Theories and evidence (pp. 79-91). London: Routledge.

Li, Y., \& Heath, A. (2008). Ethnic minority men in British labour market (1972-2005). International Journal of Sociology and Social Policy, 28(5/6), 231-244.

Li, Y., \& Heath, A. (2010). Struggling onto the ladder, climbing the rungs: Employment status and class position by minority ethnic groups in Britain (19722005). In J. Stillwell, P. Norman, C. Thomas, \& P. Surridge (Eds.), Population, employment, health and well-being (pp. 83-97). London: Springer.

Li, Y., \& Heath, A. (2016). Class matters: A study of minority and majority social mobility in Britain, 1982-2011. American Journal of Sociology, 122(1), 162-200.

Li, Y., \& Heath, A. (in press). Persisting disadvantages: A study of labour market dynamics of ethnic unemployment and earnings in the UK (2009-2015). Journal of Ethnic Minority Studies. 
Li, Y., Zhang, S., \& Kong, J. (2015). Social mobility in China and Britain: A comparative study. International Review of Social Research, 5(1), 20-34.

Lieberson, S. (1975). Rank-sum comparisons between groups. In D. Heise (Ed.), Sociological methodology (pp. 276-291). San Francisco, CA: Jossey-Bass.

May, T. (2017). Prime Minister launches world-leading project on impact of ethnicity on everyday life. Gov.Uk. Retrieved from www.gov.uk/government/ news/prime-minister-launches-worldleading-project -on-impact-of-ethnicity-on-everyday-life, accessed on $12 / 10 / 2017$

Modood, T. (2004). Capitals, ethnic identity and educational qualifications. Cultural Trends, 13(2), 87-105.

Mosteller, F. (1968). Association and estimation in contingency tables. Journal of the American Statistical Association, 63(321), 1-28.

NEP. (2007). The business commission on race equality in the workplace. London: National Employment Panel \& the EMBF 60/76.

Park, R. E., \& Burgess, E. W. (1969). Introduction to the science of sociology. Chicago, IL: University of Chicago
Press. (Original work published 1921)

Payne, G. (2017). The new social mobility: How the politicians got it wrong. Bristol: Policy Press.

Platt, L. (2005). Intergenerational social mobility of minority ethnic groups in Britain. Sociology, 39(3), 455-461.

Portes, A. (1998). Social capital: Its origins and applications in modern sociology. Annual Review of Sociology, 24, 1-24.

Sturgis, P., \& Buscha, F. (2015). Increasing intergenerational social mobility: Is educational expansion the answer? British Journal of Sociology, 66(3), 512-533.

UK Data. (n.d.). Key data. UK Data Service. Retrieved from ukdataservice.ac.uk/get-data/key-data.aspx\#/tab-uk -surveys

Vandecasteele, L. (2016). Social origin, education and socio-economic inequalities: Trends in the United Kingdom. In F. Bernhardi \& G. Ballarino (Eds.), Education, occupation and social origin (pp. 215-236). Cheltenham: Edward Elgar.

\section{About the Author}

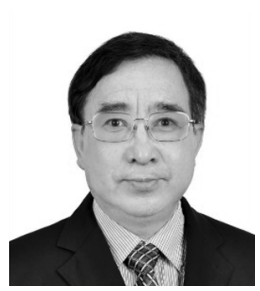

Yaojun Li is Professor of Sociology at Department of Sociology and Cathie Marsh Institute for Social Research, Manchester University, UK. His research interests are in social mobility and social stratification, social capital, socio-economic integration of ethnic minority including migrant groups and in international comparative analysis. He has published around 100 journal articles, book chapters and research reports, which have appeared in leading sociology journals in Europe and the US, book collections and government and think-tank reports. He has also conducted many research projects funded by academic and government agencies in Britain, China, the US, Australia and Qatar. 